\title{
The relative roles of input and output mechanisms in directed forgetting*
}

\author{
ROBERT H. JONGEWARD, JR. \\ University of Michigan, Ann Arbor, Michigan 41804 \\ ADDISON E. WOODWARD, JR. \\ Governors State University, Park Forest, Illinois, 60466 \\ and \\ ROBERT A. BJORK $\dagger$ \\ University of Michigan, Ann Arbor, Michigan 41804
}

\begin{abstract}
When Ss are presented a first set of items (Set A) followed by a second set (Set B), a postinput cue to recall only Set $B$ results in better recall of Set $B$ than does a cue to recall Set $B$ then Set A; to a lesser extent, the same result holds for Set A. Such "Only" effects (Epstein, 1970) have typically been attributed to selective search processes at the time of recall. In the free-recall experiment reported here, cues to remember all, only two, or none of the items in each of eight successive four-word blocks were presented either before or after a $3-\mathrm{sec}$ rehearsal period. Even though the search set at output was constant (16 to-be-recalled words), there was an Only effect for blocks followed by selective (postcue) rehearsal, whereas nonselective (precue) rehearsal produced no such effect. More striking than that result was the incredible ability of Sis, whatever the condition, to differentrate to-be-remembered and to-be-forgotten items. Set differentiation during input appears much more important as a mechanism of directed forgetting than either selective search or selective rehearsal.
\end{abstract}

In a typical directed forgetting experiment, Ss are presented a list of items to be remembered and, some time before a test of retention, they are cued to forget some of the items. Such forget cues (F cues) may occur during or following the presentation of the list and they may be applied to individual items or sets of items. In general, in those situations where an $F$ cue is effective, it both (a) eliminates the interfering effect of words cued to be forgotten ( $F$ items), thereby enhancing the retention of the remaining items ( $R$ items), and (b) drastically reduces the retrievability of the $F$ items.

Two current interpretations of the above phenomena (Bjork, 1972; Epstein, 1972) can best be contrasted in terms of the relative emphasis they place on either input or output mechanisms as the loci of directed forgetting effects. In stressing processes operating at the time of storage, Bjork (1972) has suggested that an $F$ cue is effective to the extent that (a) Ss differentially group or organize $\mathrm{R}$ items in such a way as to separate them functionally, in memory, from $F$ items and (b) Ss devote all rehearsal activities, following an $F$ cue, to $\mathrm{R}$ items. He further states that the two mechanisms really co-imply each other. "That is, efficient selective rehearsal of $R$

\footnotetext{
*This research was supported in part by the Air Force Office of Scientific Research under Contract No. F44620-72-C-0038 with the Human Performance Center, Department of Psychology, University of Michigan, and in part by Grant OEG-5-71-0023(509) from the Office of Education to the second author.

+Now at the University of California, Los Angeles. Requests for reprints should be sent to Robert A. Bjork, Department of Psychology, University of California, Los Angeles, California 90024.
}

items in memory depends on their being differentiated as a set, and the differentiation of $\mathrm{R}$ items as a set may depend on their being rehearsed together [p. 229]."

Recently, Epstein and his colleagues have challenged the role of selective rehearsal in directed forgetting (Epstein, Massaro, \& Wilder, 1972; and Shebilske, Wilder, \& Epstein, 1971). Their research activities have focused on the increased retention of $\mathrm{R}$ words as the result of an implicit postinput instruction to forget part of the presented material.

In the earliest experiments (Brown, 1954; Epstein, 1969, 1970), Ss were presented two distinct sets of items to be remembered: Set A and Set B. Following the presentation of Set $B$, one of four possible recall instructions was given. Ss were instructed to "recall Set A only," "recall Set B only," "recall Set A, then Set B," or "recall Set B, then Set A." The result of particular interest is that recall in the "Only" conditions was consistently better than recall of the first two sets recalled in the "Both" conditions. This result has been termed the "Only" effect.

Epstein (1969) has argued that the Only effect "cannot be attributed to differences in original learning. Attention and encoding may be presumed to have been the same on all learning trials since $S$ could not know in advance which output would be specified [p. 168]." Instead, he argues that the effect is due to mechanisms operating at the time of output. When Ss are responsible for recalling both sets, maintenance of the second set in memory serves as a potential source of interference 
during the recall of the first set. In the Only condition, the recall instruction functions as an implicit $F$ cue, permitting Ss to disregard the noncued set, thereby reducing interference. Shebilske, Wilder, and Epstein (1971) suggest that the Only instruction, acting as an $F$ cue, in some way tags $F$ words as inappropriate or sets the search process so that $F$ words are not considered during retrieval. Such a mechanism would reduce the interference potential of those items and would also result in fewer items being searched at the time of recall.

Clearly, the emphasis is on output mechanisms. One implication is that an opportunity for selective rehearsal of $\mathrm{R}$ words should have no bearing on the size of the Only effect. In order to test that implication, Epstein et al (1972) conducted an experiment in which both the opportunity for selective rehearsal and the size of the selective memory search set were varied. The experiment was designed to provide a direct comparison of selective rehearsal and selective search as the mechanism responsible for the Only effect and, hence, directed forgetting.

On any trial in the Epstein et al (1972) experiment, Ss were first presented three nonsense-word pairs, all three of the words coming from the same conceptual category. Then, following a 3-sec arithmetic task, three more pairs were presented with all of the responses coming from a second conceptual category. After the presentation of the second set, a recall cue was presented. The cue told the $\mathrm{S}$ that the tested pair would come from the first set, the second set, or either set. Thus, in this experiment, the "first" and "second" cues comprised the Only condition. After the cue there was a 3-sec postcue interval, and finally, a retention test. Opportunity for selective rehearsal was manipulated by either leaving the postcue interval empty, thereby permitting rehearsal, or having the $S$ engage in a rehearsal preventing arithmetic task during the postcue interval. At the same time, the size of the memory search set was manipulated by the use of two tests, a recall test and a matching test. On the recall test, one stimulus element was presented and the $S$ was asked to supply the correct response (paired-associate probe). Here the Only cues could be expected to restrict the number of alternatives considered as compared to the "Either" Condition, a restriction that should result in an Only effect. On the matching test, one stimulus term was presented along with all three responses from the set being tested, and Ss were to select the correct response. If differences in search set size are responsible for the Only effect, the effect should not be observed on the matching test since the Ss needed to consider only three items in both the Only and Either conditions. The results supported that expectation. The main effect of test type resulted in a significant Only effect with the recall test but not with the matching test. At the same time, the rehearsal manipulation produced no difference. Under both rehearsal conditions, the recall test yielded a significant Only effect.

While some mechanism that differentiates the two sets must be operating at input, Epstein et al (1972) argue, on the basis of these results, that an F cue has its effect at the time of output. They suggest that "the Forget cue provides $\mathbf{S}$ with a list tag that can be used to eliminate the to-be-forgottein (incorrect) items as acceptable responses at test [p. 18]." Since the rehearsal manipulation in their experiment did not have a differential effect on the magnitude of the Only effect, they further state that encoding variables such as selective rehearsal do not play an important role in directed forgetting, at least not in the context of the Only effect.

The adequacy of the Epstein et al experiment as a critical test of selective rehearsal in directed forgetting can be questioned on several grounds.

(1) As was pointed out earlier, implicit in Bjork's characterization of directed forgetting is the notion that set differentiation and selective rehearsal co-imply one another. Typically, it has been assumed that the type of rehearsal that establishes $\mathbf{R}$ words as a single and functionally separate set is a process in which Ss attempt to process all $\mathrm{R}$ words in the same "rehearsal scheme [Bjork, 1972]." Ss develop interassociations among the individual $\mathrm{R}$ words so as to establish them as an integrated set of interrelated items. On logical grounds alone, this does not appear to be the most efficient strategy for an S to adopt when faced with a typical paired-associate (PA) task. Presumably, in a PA experiment, the $S$ tries to encode any one pair in such a manner that, when later presented only the stimulus, he can respond with the correct response. To the extent that Ss attempt to interassociate separate pairs, they create potential sources of interference that may handicap their production of the correct response when a stimulus probe is presented. The PA paradigm, then, is not the most appropriate task to use when trying to test the importance of selective rehearsal in directed forgetting.

(2) A more crucial problem is that directed forgetting, defined exclusively in the context of the Only effect, may not be a case of "forgetting" at all. In all of the experiments by Epstein and his coworkers (reviewed in Epstein, 1972), the various recall instructions have been presented either immediately prior to recall or, at most. just $3 \mathrm{sec}$ prior to recall. If the Only cues serve to direct the S's attention to a smaller set of possible alternatives, then the Only effect may simply be a case of cued recall being better than uncued (or less cued) recall. To illustrate this point consider the following hypothetical PA experiment: Ss are presented two sets of word-word pairs, the pairs in one set printed in red letters, the pairs in the other set printed in blue letters. After seeing the entire list, one group of Ss is presented a stimulus probe 
printed in a neutral color. The second group is presented a stimulus probe printed in a discriminative color, that is, the color in which the tested pair was initially presented. It seems quite reasonable to expect higher recall from the second group, not through the operation of any forgetting mechanism, but simply because they are given more stimulus information at the time of test. Thus, although Epstein et al choose to call the Only cue an $\mathrm{F}$ cue, its primary effect may be that it adds to the cue value of the subsequent stimulus probe. For this reason, the Only effect may not be the result of directed "forgetting" as much as it is the result of directed retrieval.

(3) Another minor problem, but one worthy of comment, deals with the methods that have been employed to manipulate the opportunity for rehearsal. Most investigators (the authors included) are willing to accept the notion that activities such as shadowing digits, doing arithmetic, and so on "prevent" rehearsal. Still, one wonders how often Ss are able to rehearse surreptitiously while performing such tasks. Epstein et al (1972) report that $8 \%$ of their Ss, when questioned after the experiment, reported being able to rehearse during all of the subtraction tasks while an additional $6 \%$ were able to rehearse at least during the easier problems. Although this is a small percentage of Ss rehearsing in the no-rehearsal condition, it would be desirable to eliminate completely all such rehearsal.

The experiment reported in the present paper was designed to test the role of selective rehearsal in the Only effect while taking into consideration the problems outlined above. The experiment was a free recall task in which Ss were presented 32-word lists, each of which was divided into eight four-word blocks. Following each block, a cue was presented either before or after a rehearsal period; the cue instructed Ss to remember all, only part of, or none of the words in that block. A free recall paradigm was employed because of its suitability as a context in which to manipulate rehearsal as an interassociative activity. At the end of any one list, Ss were asked to recall all the $\mathrm{R}$ words from that list and to avoid recalling any $F$ words. At the end of the experiment, Ss were asked to recall as many words as they could, from any list in the experiment regardless of their initial cueing. All Ss in this experiment were treated the same except for the opportunity provided for rehearsal. The cuing period after each block lasted $4 \mathrm{sec}$ in every case. For one group of Ss, the recall cue was on for the entire period, permitting several seconds for selective rehearsal of the to-be-remembered words following the processing of the cue. However, for the other group the cue was presented only during the final $1 \mathrm{sec}$ of the 4-sec cuing period. During the initial $3 \mathrm{sec}$, the Ss had to maintain the four-word block in memory, but it was logically impossible for them to rehearse selectively the to-be-remembered words because they did not yet know which ones they were.
The experimental design avoids several problems inherent in the design of earlier Only-effect studies.

(a) The possibility of cued recall was eliminated since the Only and All instructions appeared throughout the presentation of the 32-word lists.

(b) In the earliest Epstein studies $(1969,1970)$ in which free recall was used, Ss were always responsible for recalling more total words when asked for all of the list than when they were cued that only part of the list would be tested. In this experiment, Ss were asked to recall 16 words after each list, half of those words coming from Only blocks (only part of the block was to be remembered) and the other half of the words coming from All blocks.

(c) As was pointed out above, selective rehearsal of to-be-remembered words was a logical impossibility for one group in the experiment since they did not receive the cue designating which words were to be remembered until the end of the cueing period.

It was expected that a significant Only effect would obtain only for the Ss who were provided time to rehearse selectively the to-be-remembered material. Such a result would be especially impressive since, however one might choose to define it, the size of the memory search set at the time of recall was the same for both groups.

The cue to Ss to forget all of the items in a block was included in the experimental design to test the notion that the longer an item is held in memory, the harder it would be to forget that item. It was expected that the first item in a block would be more difficult to forget than the last item in a block; that is, the first item would have a higher intrusion rate on immediate recall and higher probability of recall on a final recall test than later items in the block.

\section{METHOD}

\section{Subjects}

Forty Ss drawn from the University of Michigan volunteer S pool participated in the experiment. They were paid $\$ 1.50$ plus any bonuses that accrued from the payoff system employed in the experiment.

\section{Materials and A pparatus}

Every $S$ viewed five 32-word lists composed of common, four-letter nouns. All materials presented to the $S$ during the experiment appeared in the same window of a high-speed memory drum (change time less than $.05 \mathrm{sec}$ ). The timing of advances of the memory drum was controlled by a high-speed paper-tape reader. Ss were supplied with an answer booklet for the immediate recall test (one page for each list plus several extra pages) and a single sheet of paper for the final recall test.

\section{Design}

Each list was composed of eight blocks of four words (each word being presented individually). Following every block of four words, a cue appeared telling the $S$ which of the words in the immediately preceding block of four were to be remembered. Four different cues were used: $R R F F$-remember the first two words in that block and forget the last two words 
(thus in that block, Words 1 and 2 were $\mathrm{R}$ words and Words 3 and 4 were $F$ words), FFRR-forget the first two words and remember the last two, $R R R R$-remember all four words, and $F F F F$-forget all four words. Each cue was randomly assigned to one of the first four blocks in a list and again to one of the last four blocks. Counterbalancing proced ures insured that, across Ss, each block in a list was followed equally often by each of the four cues; each word in a list, therefore, appeared equally often as an $\mathrm{R}$ word and as an $\mathrm{F}$ word. This proced ure also eliminated a confounding of cuing condition with serial position. After each list, there was an immediate free recall test during which Ss were asked to recall $R$ words and to avoid recalling $F$ words. After all five lists had been presented and recalled, there was a final recall during which Ss were asked to recall all words from all lists.

\section{Procedure}

Twenty Ss were tested in the selective-rehearsal condition (S-rehearsal group) and then another group of $20 \mathrm{Ss}$ were tested in the nonselective-rehearsal condition (NS-rehearsal group). Each $\mathrm{S}$ was read a set of instructions and was shown two practice lists, each of which consisted of 16 nonsense syllables, before the experiment began.

Each list was preceded by a $3-\mathrm{sec}$ ręady signal. The individual words within a list were presented for $2.3 \mathrm{sec}$. Immediately following the off set of every fourth word, the 4-sec cuing period began. The only difference between the two groups of $\mathrm{Ss}$ in this experiment was the structure of the cuing period. For the $20 \mathrm{Ss}$ in the S-rehearsal group, the cue was presented at the onset of the cuing period and it remained in view for the entire $4 \mathrm{sec}$. For the Ss in the NS-rehearsal group, the window remained blank for the initial $3 \mathrm{sec}$, and the cue was shown for only the final $1 \mathrm{sec}$ of the 4-sec cuing period. During the cuing period, all Ss were instructed to confine their rehearsal to the current block. Upon termination of this period, the first word of the next four-word block was shown immediately.

At the end of each list, a recall signal was presented and it remained in view for $45 \mathrm{sec}$. During this period, Ss were required to write down as many $\mathrm{R}$ words as they could remember. Ss received a one-cent bonus for each $\mathrm{R}$ word recalled, and they were penalized one cent for each $F$ word intruded. After the recall of the last list there was a debriefing period lasting several minutes, after which $S s$ were asked to recall all the words presented during the experimental session, $F$ words as well as $R$ words. Each item recalled earned a one-cent bonus regardless of its initial cuing.

\section{RESULTS}

\section{Immediate Recall}

In Fig. 1, the probability of immediate recall under all four cuing conditions is plotted as a function of serial position within a block. These data are summed across all eight blocks in a list and across all five lists in the experiment. (The data were also scored deleting the first and last blocks of each list, but since no interaction was found between Only and All recall and serial position in the list, data from all eight blocks are included in this and all subsequent analyses.) Plotted in the top panel are the data for the S-rehearsal group and plotted in the bottom panel are the data for the NS-rehearsal group. The recall probability for $F$ words plotted in these two graphs represents the intrusion rate for these items since Ss were instructed not to recall these words on the immediate test.
Overall, the forget instructions were remarkably effective in this experiment. This result is especially impressive for the NS-rehearsal group. Before these Ss were shown the 1 -sec cue, they were required to process the set of four words for $9.2 \mathrm{sec}$ during input and then were required to rehearse the whole set for an additional $3 \mathrm{sec}$ following the input. During all of this time there was no basis on which to give differential processing to $R$ words. Given these striking results, it appears that whatever the mechanism responsible for the Only effect, the overall difference in the recall of $\mathrm{R}$ and $\mathrm{F}$ items must be primarily attributable to set differentiation during input.

In this experiment, the Only effect is defined as superior recall of $\mathrm{R}$ words in the $R R F F$ and FFRR (Only) conditions when compared to the recall of $R$ words in the RRRR (All) condition. For the S-rehearsal group, overall probability of $\mathrm{R}$ word recall in the $R R \mathrm{FF}$ and FFRR conditions was 375 , in the $R R R R$ condition, .300 . The .075 superiority under the Only conditions (taken as a measure of the Only effect) is significant $[F(1,16)=9.17, p<.01, \quad S E=.018]$. For the NS-rehearsal Ss, on the other hand, overall probability of $\mathrm{R}$ word recall in the $R R F F$ and FFRR conditions and the $R R R R$ condition was .360 and .345 , respectively, a difference that is not significant $[\mathrm{F}<1, \mathrm{SE}=.020$. Thus, when Ss are provided time to selectively rehearse $R$ words following the cue, a significant Only effect is observed; when, however, the opportunity for selective rehearsal is restricted severely, if not completely eliminated, there is no Only effect. As was pointed our earlier, this result is all the more impressive in light of the fact that the size of the memory search set must be considered identical under both conditions.

In Fig. 1 there is an apparent triple interaction of Rehearsal Group by Only vs All Conditions by Serial Position. The existence of such an interaction might have important implications for the definition of the Only effect, but since the interaction is not statistically significant, speculating about those implications seems unwarranted.

Evidence that Ss in the S-rehearsal group were in fact engaging in selective rehearsal comes from the following analysis. Given the nature of the cues used in the experiment, the words in Serial Positions 1 and 2 in any block were always cued the same regardless of instruction, as were the words in Serial Positions 3 and 4: whatever the cue, both were $R$ words or both were $F$ words. For that reason, early in the experiment, Ss might have tried to process each four-item block as two two-item units. If that was the case, one might expect that the immediate recall of a particular item given recall of the other item in the same half block ("same-half" item) would be greater than recall of that item given recall of an item in the other half block ("different-half" 


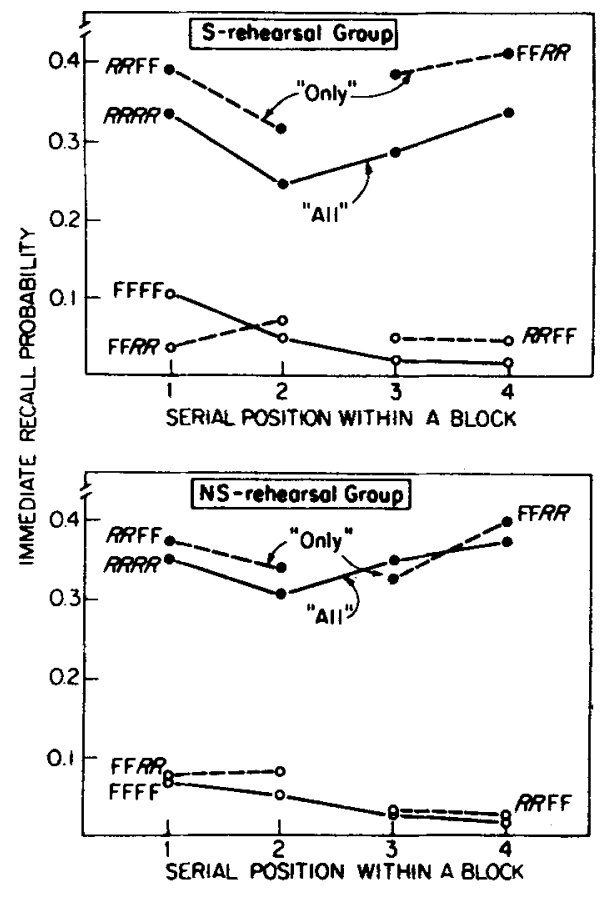

Fig. 1. Probability of immediate recall as a function of serial position within a block for all four cuing conditions.

item). Table 1 indicates that there was a tendency to separate each block into two halves and then to rehearse accordingly. That is, the probability of recall given the recall of the other "same-half" item is higher $[t(39)=2.859, \quad p<.01, \quad S E$ of the mean difference $=.034$ ] than the probability of recall given the recall of one of the "different-half" items for both groups taken together (the RRRR Row in each half of Table 1).

The most important comparison is between the Only (RRFF and FFRR) conditions and the All (RRRR) condition within each group. If, following an Only cue, Ss are devoting all their time to rehearsing only Words 1 and 2 or Words 3 and 4 (depending on the cue) then those words will function as stronger retrieval cues for each other than in the All condition since there the $S$ must divide his time between worcessing Words 1 and 2 and Words 3 and 4 . That is, the probability of recalling an item given the other "same-half" item should be higher in the Only conditions than in the All Condition. Such a superiority is obtained under the S-rehearsal condition $[t(19)=2.7659, p<.01$, SE of the mean difference $=.052$ ] where selective rehearsal is presumed to be taking place but there is no difference for the NS-rehearsal Ss where selective rehearsal is prevented.

\section{Final Recall}

The probability of final recall is plotted in Fig. 2 in the same manner as the immediate recall data are plotted in Fig. 1. Typically, final recall performance is taken as a measure of the comparative availability of $R$ and $F$
Table 1

Immediate Recall Probability of $R$ Words Given Recall of Another R Word from the Same or Different Half Block Within Any One Four-Item Block

\begin{tabular}{lcc}
\multicolumn{1}{c}{ Cue Type } & \multicolumn{1}{c}{$\begin{array}{c}\text { Same } \\
\text { Half Block }\end{array}$} & $\begin{array}{c}\text { Different } \\
\text { Half Block }\end{array}$ \\
\hline RRRR & S-Rehearsal Group & \\
$R R$ FF or FFRR & $.444(\mathrm{SE}=.045)$ & $.362(\mathrm{SE}=.043)$ \\
& $.588(\mathrm{SE}=.036)$ & \\
$R R R R$ & NS-Rehearsal Group & \\
$R R F F$ or FFRR & $.531(\mathrm{SE}=.052)$ & $.394(\mathrm{SE}=.037)$ \\
\hline
\end{tabular}

words since during the final recall task Ss are instructed (and rewarded) for recalling any word from the experiment regardless of its original designation. In Fig. 2, $\mathrm{R}$ word recall has decreased from its level on the immediate test, but it has not fallen to the level of the $\mathrm{F}$ words. One might argue that the superiority of $\mathrm{R}$ words in final recall is attributable to their having a higher likelihood of being recalled immediately. In other words, recall of a word on the immediate test might enhance the probability of that word being recalled on the final test. A recent study conducted by Bjork and Woodward (1973) shows that such is not the case. In their experiment, Ss were presented 24-word lists in each of which 12 words were followed by remember cues and the other 12 words were followed by forget cues. Half of the lists were followed by a 30 -sec free-recall test (for $R$ words) and half of the lists were followed by $30 \mathrm{sec}$ of digit shadowing (no recall). The results indicate that "The final recall of $R$ words and $F$ words from lists that were not followed by an immediate recall reveals the same relative advantage of $\mathrm{R}$ words over $\mathrm{F}$ words as is shown in the final recall of words from lists that were followed by an immediate recall [p. 24]." These data suggest that differences in final recall of $\mathrm{R}$ words and $\mathrm{F}$ words arise from differential processing during input rather than facilitation of final $R$-word recall due to their higher probability of recall on the immediate test.

For the S-rehearsal Ss, the significant Only effect continues to exist in final recall. The overall probability of recall under the Only conditions is .176 as compared to .126 under the All condition. This difference is significant $[F(1,16)=8.38, p<.025, \mathrm{SE}=.012]$. On the other hand, there is no only effect present in the final recall of the NS-rehearsal group. Overall probability of recall under the Only conditions (.158) is not significantly higher than that under the All condition (.146) $[\mathrm{F}<1, \mathrm{SE}=.011]$. As in immediate recall (Fig. 1) there is an apparent triple interaction of Rehearsal Groups by Only vs All Conditions by Serial Position. However, as in immediatee recall, this interaction is not statistically significant.

A cue to forget all items in a block (FFFF) was included in order to examine the notion that the longer an item is held in memory, the harder it would be to 


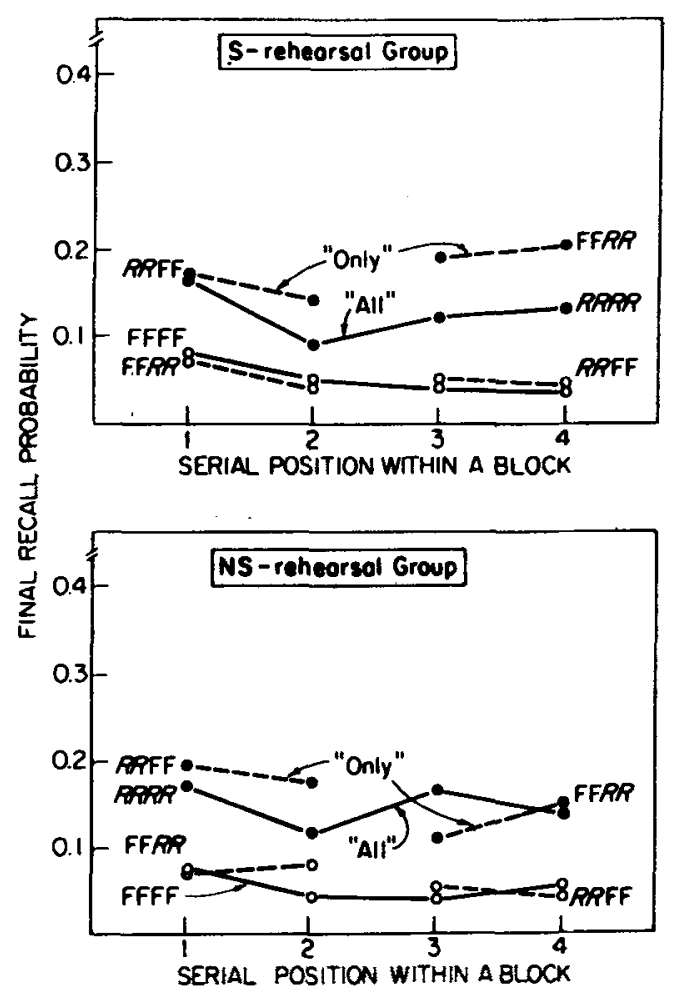

Fig. 2. Probability of final recall as a function of serial position within a block for all four cuing conditions.

forget that item. In immediate recall, the drop in $F$ word intrusions across block serial positions in this cuing condition is significant for both the S-rehearsal and NS-rehearsal groups $[\mathrm{F}(3,48)=3.15, \mathrm{p}<.05, \mathrm{SE}=.011$; $\mathrm{F}(3,48)=6.10, \mathrm{p}<.01, \mathrm{SE}=.010$, respectively $]$. There were no significant block serial position effects in the final recall data for either group. Even though the effect is significant in immediate recall, the drop is very slight. It seems that the amount of time an item is maintained in memory, prior to a cue, has little bearing on the S's ability to forget that item.

\section{DISCUSSION}

When taken together, the results of this study and those of the Epstein et al (1972) study, at first, appear rather perplexing. In both studies, a significant Only effect was obtained and yet the necessary conditions for such an effect are really the opposite in the two experiments. On the one hand, Epstein et al (1972) found a significant Only effect to be a function of the relative size of the memory sets through which Ss search under the Only and Either conditions. When the Only cue narrowed the number of alternatives in compa rison to the Either cue, then there was an Only effect. This effect was obtained independent of whether Ss were or were not given the opportunity to engage in selective rehearsal of the to-be-remembered material. However, in the present experiment, a significant Only effect was obtained only when Ss were given a chance to selectively rehearse the to-be-remembered material. This was true despite the fact that the size of the memory search set was the same under both the S-rehearsal and NS-rehearsal conditions.

This contradiction proves bothersome only if one's attention is limited to the original operational definition of the Only effect. It is true that an Only effect, defined as superior recall for part of a list when only part is required as opposed to when the whole list is required, was obtained in both cases. Restricting oneself to this simple definition, however, obscures the possibility that there may be two entirely different phenomena being observed in the two experiments. To illustrate this point, attention should be turned to two aspects of the current study, both involving final recall.

It is the contention of Epstein et al (1972) that the Only effect arises from presenting a cue just prior to recall that, in some way, designates the appropriate items in memory to be searched; the set being smaller on Only trials than on Either trials. If such were the case, then on a final recall test where the $S$ is told to recall any item he can remember, it seems difficult to imagine A $S$ being able to set up a smaller search set for Only items. Thus, by this reasoning, an Only effect would not be expected in the final recall data. However, for S-rehearsal Ss in this experiment, such an effect was obtained. While the Only effect in final recall was smaller, in absolute terms, than in immediate recall, the percentage increase in $\mathrm{R}$ word recall in the $R R F F$ and FFRR conditions over that in the $R R R R$ condition was about the same and the effect was significant. The selective search hypothesis of Epstein et al (1972) seems incapable of handling these data.

A second point stressed by Epstein and Wilder (1972) is the following: If an Only cue operates by designating the relevant to-be-recalled (TBR) items, then to-be-forgotton (TBF) items should not show a decrement in recall when they become the appropriate items. They predicted that when Ss were informed that TBF items were being tested then TBF recall would not differ from Only TBR recall. In fact, they found "informed" TBF recall to be lower than Only TBF recall, but not significantly different from TBR recall in the Either condition. In the present experiment, a final recall test was employed to provide an index of the comparative availability of $R$ and $F$ items. From the final recall data in Fig. 2, it is apparent that $F$ words are nowhere near as available as $R$ words.

Further support for this second point comes from a recent experiment performed by Woodward, Seebohm, and Cortis (1974) employing both implicit and explicit $F$ cues. In each free recall list there were three types of items designated as such by a color cue following each item. Ss were instructed to forget any item followed by a black dot, and they were instructed to remember any item followed by either a red dot or a blue dot (half of 
the remember items were followed by red dots and half were followed by blue dots). Various recall instructions were given just prior to the recall test following any one list (recall red only, recall blue only, recall red then blue, recall blue then red, and recall all). Items cued as to-be-forgotten items were intruded less on immediate recall, recalled less on final recall, and recognized less often on a final recognition test than items cued as to-be-remembered items, but not tested on the immediate recall. Thus, although there were no postinput differences in the treatment of the two types of items, they differed greatly in availability at the time of final recall.

It is not the authors' intention to dispute the fact that Epstein et al (1972) observed a significant Only effect or that it happened for the very reasons that they state. The point is that the Only effect observed here was a very differnt phenomenon. Had Epstein et al (1972) included some type of final recall test in their design, it is doubtful that they would have obtained the same low level of TBF recall that was obtained in the present experiment. The difference in the fate of $F$ items in the two experiments illustrates the need for a finer distinction between the various phenomena that fall under the general heading of "directed forgetting."

The results of the present experiment, the experiments conducted by Epstein and his coworkers and the experiments of other investigators as well (for a review see Bjork, 1972), indicate that one of the general effects of an $F$ cue, either implicit or explicit, is the improved retention of words not cued to be forgotten. It now appears that this result can be attributed to different processes in different task situations. On the one hand, the results of the present experiment indicate that input mechanisms, such as selective rehearsal, operating at the time of storage are responsible for the improved retention of TBR material. When the $S$ can work to acquire good retrieval cues for a smaller set of items by means of selectively rehearsing only those items, then the retrieval cues for any given item will be stronger than they would be if the $S$ were responsible for all the items. This will result in improved recall of the TBR items compared to recall of the list as a whole.

Alternatively, given that the $S$ has acquired retrieval cues equally well for two distinct sets of items, an implicit cue to forget one of the sets, given immediately before output, will still result in higher recall of the TBR set because it directs the S's retrieval processes to a smaller set of relevant items than would be the case if the $\mathrm{S}$ were responsible for the entire list.

In both of these cases, the typical "directed forgetting" results of improved TBR recall is obtained. However, the effect cannot be specifically attributed to either input or output mechanisms until careful consideration is given to the actual task that the $\mathrm{S}$ faced.
Finally, the general absence of any serial position effect in the $\mathrm{F}$ word recall data is understandable in light of two recent studies we have conducted to investigate rehearsal processes. In the present experiment it was assumed that the longer an item was held in memory, the more difficult it would be to forget that item. The two subsequent studies we have performed indicate this is not the case (Bjork \& Jongeward, 1974; Woodward, Bjork \& Jongeward, 1973). In both of these experiments rehearsal as a rote repetition activity ("primary" rehearsal) was contrasted with rehearsal as an interassociative, integrative process ("secondary" rehearsal). It was shown that merely maintaining information in short-term memory by some rote repetition process (primary rehearsal) has no subsequent effect on the long-term retrievability of that information. In the present study it appears that Ss were simply maintinaing the four-word blocks in memory until the cue was presented. Any activity to further encode the material in a long-term sense would of ter have been counterproductive since Ss were periodically cued to forget such material. For that reason, the first item in a block was no harder to forget than later items.

\section{REFERENCES}

Bjork, R. A. Theoretical implications of directed forgetting. In A. W. Melton \& E. Martin (Eds.), Coding processes in human memory. Washington, D.C: Winston, 1972.

Bjork, R. A., \& Woodward, A. E. Directed forgetting of individual words in free recall. Journal of Experimental Psychology, 1973, 99, 1, 22-27.

Brown, J. The nature of set-to-learn and of intra-material interference in immediate memory. Quarterly Joumal of Experimental Psychology, 1954, 6, 141-149.

Epstein, W. Poststimulus output specification and differential retrieval from short-term memory. Journal of Experimental Psychology, 1969, 82, 168-174.

Epstein, W. Facilitation of retrieval resulting from postinput exclusion of part of the input. Journal of Experimental Psychology, 1970, 86, 190-195.

Epstein, W. Mechanisms of directed forgetting. In G. H. Bower (Ed.), The psychology of learning and motivation, Vol,6. New York: Academic Press, 1972.

Epstein, W., Massaro, D., \& Wilder, L. Selective search in directed forgetting. Journal of Experimental Psychology, 1972, 94, 18-24.

Epstein, W., \& Wilder, L. Searching for to-be-forgotten material in a directed forgetting task. Joumal of Experimental Psychology, 1972, 95, 349-357.

Shebilske, W., Wilder, L., \& Epstein, W. Forget instructions: The effect of selective rehearsal and categorical distinctiveness. Journal of Experimental Psychology, 1971, 89, 372-378.

Woodward, A. E., Bjork, R. A., \& Jong ew ard, R. H. R ecall and recognition as a function of primary rehearsal. Journal of Verbal Learning and Verbal Behavior, 1973, 12, 608-617.

Woodward, A. E., Seebohm, K., \& Cortis, D. Directed forgetting as a function of explicit within-list cuing and implicit post-list cuing. Journal of Experimental Psychology, 1974, in press.

\section{NOTE}

1. R. A. Bjork and R. H. Jongeward. Primary and secondary rehearsal. Submitted for publication, 1974.

(Received for publication March 28, 1974 , revision received May 28,1974 ,) 